\section{In vivo confocal microscopy of early corneal epithelial recovery in patients with chemical injury}

J Xiang ${ }^{1,4}, Q L^{1,2,3,4}, Y L^{1,3}$ and J Xu ${ }^{1,3}$
${ }^{1}$ Department of

Ophthalmology, Eye \& ENT

Hospital of Fudan

University, Shanghai,

China

${ }^{2}$ Research Center, Eye \& ENT Hospital of Fudan University, Shanghai,

China

${ }^{3}$ Myopia Key Laboratory of Ministry of Health, Eye \& ENT Hospital of Fudan University, Shanghai,

China

Correspondence:

J Xu, Department of Ophthalmology, Eye \& ENT Hospital of Fudan University, Shanghai 200031, China Tel: +862164377134 ext 706;

Fax: +862164377151. E-mail: jianjiang-xu@163.com

${ }^{4}$ These authors contributed equally to this work.

Received: 19 November 2014 Accepted in revised form:

11 July 2015

Published online:

18 September 2015

\begin{abstract}
Purpose To investigate the early recovery of corneal epithelium in patients with chemical injuries by the application of in vivo laser scanning confocal microscopy (LSCM). Methods LSCM was performed on 26 eyes of 18 consecutive patients at 1,2 , and 3 months post injury. The morphology of central corneal epithelium and limbus was evaluated. Analysis was performed to compare the densities of corneal apical surface cells (ASCs) and basal epithelial cells (BECs) among different injury severity and time points after injury. The comparisons were also made on inflammatory cells (ICs) and dendritic cells (DCs) infiltrating at the limbus. Moreover, the presence rate of palisades of Vogt (POV) was analyzed at 3 months post injury.

Results Corneal re-epithelialization was found within 3 months post injury in all eyes, except that persistent epithelium defect was identified in grade IV injured eyes even at 3 months after injury. The injury severity had a significantly negative correlation with the densities of ASCs. However, it had no relationship with the densities of BECs. The density of ICs at the limbus decreased significantly with the prolongation of follow-up, except in the grade I injured eyes. The presence rate of POV also had a significantly negative correlation with injury severity.

Conclusion Epithelial recovery after chemical injury varied in cellular morphology and the densities of ASCs among eyes with different injury severity. The presence rates of POV decreased with the aggravation of injury. LSCM is a feasible method for observing the early recovery of corneal epithelium in patients with chemical injuries.

Eye (2015) 29, 1570-1578; doi:10.1038/eye.2015.172;

published online 18 September 2015
\end{abstract}

Introduction

Ocular chemical injury, one of the leading causes of corneal blindness, is often encountered in ophthalmology emergency room, especially in developing countries. Severe ocular chemical injury often leads to limbal stem cell deficiency, which is characterized by corneal epithelium conjunctivalization, marked inflammatory cell infiltration, extensive scar formation, and neovascularization. These processes usually lead to severe loss of corneal transparency and even permanent blindness. ${ }^{1}$

Corneal epithelium defect may occur soon after chemical burns because of direct damage caused by chemical agent, and could last for a long time owing to consequent limbal stem cell deficiency and/or stromal abnormality. ${ }^{2}$ It is of great importance to evaluate the recovery of corneal epithelial cells at early stage after injury because it has a close relationship with final prognosis. ${ }^{1}$ However, the clinical assessment of corneal epithelium mainly depends on slit lamp microscopy at present. Slit lamp examination cannot provide detailed corneal structures at the cellular level. Other techniques, such as biopsy and/or impression cytology, are difficult to perform at the early stage after injury, as the edematous ocular tissue and excessive tearing might cause disturbance in the process of sampling and reduce the number of cells harvested. Moreover, these techniques are invasive and time-consuming.

In vivo laser scanning confocal microscopy (LSCM), a rapid and non-invasive technology, has facilitated ophthalmic clinicians and researchers to visualize corneal tissue at high resolutions. Its application has been popularized in observing the morphological alterations of ocular surface under pathological conditions, including chemical burns. ${ }^{3-7}$ The purpose of this study was to investigate the early recovery of corneal 
epithelium in patients with chemical injuries with the application of LSCM, and explore its correlation with the injury severity. To the best of our knowledge, it has never been reported previously.

\section{Materials and methods}

\section{Subjects}

The study was conducted in compliance with informed consent regulations and the Declaration of Helsinki, and was approved by the Ethics Committee of Shanghai Eye, Ear, Nose, and Throat Hospital. Eighteen Chinese patients (14 men and 4 women) with ocular chemical injuries, who were referred to the Shanghai Eye, Ear, Nose, and Throat Hospital for ocular care between September 2009 and November 2011, were enrolled in the study. They are all Chinese Mongolian race, with an average age of $40.0 \pm 13.6$ years (range from 9 to 62 ). A total of 26 eyes were included in the study, among which 5 were acid burn, and the rest were alkali burn. According to the Roper-Hall classification, ${ }^{8}$ five eyes were classified as grade I injury, nine eyes grade II, six eyes grade III, and six eyes grade IV. The demographic data are shown in Table 1. Subjects with previous ocular surgery or trauma, history of recurrent corneal epithelial defect, contact lens wear history and ocular, or systemic disease that could potentially affect epithelial healing were excluded. Another 18 age- and gender-matched healthy subjects were enrolled, with an average age of $38.5 \pm 10.9$ years (range from 18 to 58 ). Only one eye was randomly chosen in each healthy subject, serving as the control group.

\section{Post-injury management}

All patients initially were subjected to first-aid therapy, which included copious and continuous irrigation with $0.9 \%$ saline solution to normalize the ocular surface $\mathrm{pH}$ and removal of any particulate matter or debris as appropriate. The irrigation lasted for at least half an hour. Following rinsing and initial assessment, medical treatment was instituted, which included topical levofloxacin 0.5\% QID, dexamethasone 0.1\% QID, preservative-free lubricants Q2H, tropicamide 1\% BID and oral vitamin C $500 \mathrm{mg}$ QID for 2-4 weeks.

Topical timolol maleate and/or oral acetazolamide were used in subjects with elevated intraocular pressure. All enrolled eyes underwent amniotic membrane transplantation within 1 week after injury except five eyes with grade I injury. The patients were asked to follow-up at the first, second, and third month after injury.

Table 1 Demographic features of enrolled subjects

\begin{tabular}{|c|c|c|c|c|c|c|c|}
\hline Patient No. & Gender & Affected eye & Injury agent & Grade of injury & $A M T$ & Limbal ischemia & Location of POV \\
\hline \multirow[t]{2}{*}{1} & \multirow[t]{2}{*}{ Male } & Right eye & Alkali & 1 & No & None & Inferior \\
\hline & & Left eye & Alkali & 1 & No & None & Inferior \\
\hline \multirow[t]{2}{*}{2} & \multirow[t]{2}{*}{ Male } & Right eye & Alkali & 1 & No & None & Inferior \\
\hline & & Left eye & Alkali & 2 & Yes & $<1 / 3$ & Absent \\
\hline \multirow[t]{2}{*}{3} & \multirow[t]{2}{*}{ Male } & Right eye & Alkali & 1 & No & None & Inferior \\
\hline & & Left eye & Alkali & 3 & Yes & $1 / 3-1 / 2$ & Inferior \\
\hline \multirow[t]{2}{*}{4} & \multirow[t]{2}{*}{ Male } & Right eye & Alkali & 1 & No & None & Inferior \\
\hline & & Left eye & Alkali & 2 & Yes & $<1 / 3$ & Inferior \\
\hline 5 & Male & Right eye & Alkali & 2 & Yes & $<1 / 3$ & Superior inferior \\
\hline 6 & Male & Left eye & Alkali & 2 & Yes & $<1 / 3$ & Inferior \\
\hline 7 & Male & Right eye & Alkali & 2 & Yes & $<1 / 3$ & Inferior \\
\hline \multirow[t]{2}{*}{8} & \multirow[t]{2}{*}{ Male } & Right eye & Alkali & 4 & Yes & $>1 / 2$ & Absent \\
\hline & & Left eye & Alkali & 2 & Yes & $<1 / 3$ & Inferior \\
\hline \multirow[t]{2}{*}{9} & \multirow[t]{2}{*}{ Male } & Right eye & Alkali & 4 & Yes & $>1 / 2$ & Absent \\
\hline & & Left eye & Alkali & 2 & Yes & $<1 / 3$ & Inferior \\
\hline \multirow[t]{2}{*}{10} & \multirow[t]{2}{*}{ Female } & Right eye & Acid & 2 & Yes & $<1 / 3$ & Absent \\
\hline & & Left eye & Acid & 2 & Yes & $<1 / 3$ & Absent \\
\hline 11 & Male & Right eye & Alkali & 3 & Yes & $1 / 3-1 / 2$ & Inferior \\
\hline 12 & Male & Left eye & Alkali & 3 & Yes & $1 / 3-1 / 2$ & Inferior \\
\hline 13 & Female & Right eye & Alkali & 3 & Yes & $1 / 3-1 / 2$ & Inferior \\
\hline \multirow[t]{2}{*}{14} & \multirow[t]{2}{*}{ Female } & Right eye & Acid & 3 & Yes & $1 / 3-1 / 2$ & Absent \\
\hline & & Left eye & Acid & 4 & Yes & $>1 / 2$ & Absent \\
\hline 15 & Male & Right eye & Alkali & 3 & Yes & $1 / 3-1 / 2$ & Absent \\
\hline 16 & Female & Right eye & Alkali & 4 & Yes & $>1 / 2$ & Absent \\
\hline 17 & Male & Left eye & Alkali & 4 & Yes & $>1 / 2$ & Absent \\
\hline 18 & Male & Left eye & Acid & 4 & Yes & $>1 / 2$ & Absent \\
\hline
\end{tabular}

Abbreviations: AMT, amniotic membrane transplantation; POV, palisades of Vogt. 


\section{In vivo $L S C M$}

At each time point, the injured eyes were examined using Heidelberg retina tomograph/Rostock cornea module (HRTIII/RCM) (Heidelberg Engineering GmbH, Dossenheim, Germany), with a $60 \times$ water-immersion objective lens (Olympus Europa GmbH, Hamburg, Germany) and a 670-nm diode laser as a light source. The acquired two-dimensional images consist of $384 \times 384$ pixels covering an area of $400 \mu \mathrm{m} \times 400 \mu \mathrm{m}$ with transversal optical resolution of $2 \mu \mathrm{m}$ and longitudinal optical resolution of $4 \mu \mathrm{m}$. One drop of $0.4 \%$ oxybuprocaine hydrochloride (Benoxil; Santen Pharmaceutical, Osaka, Japan) was instilled to the lower conjunctival sac before the examination. Patients were seated in front of the microscope, with their head steadied with the aid of a headrest and with the eye properly aligned to obtain a tangential optical section of the central cornea and limbus. They were asked to follow a dedicated mobile bright white light provided with the instrument with the fellow eye. The central cornea of the injured eye was examined first, and followed by the superior, inferior, temporal, and nasal limbus.

\section{Image analysis}

All images were subsequently checked by a masked observer. Before cellular density calculation, the images of central corneal epithelium, and the limbus with inflammatory cells (ICs) and dendritic cells (DCs) were selected out and encoded. At the early recovery period after injury, it is difficult to precisely identify the corneal epithelial cells at different depth. Basal epithelial cells (BECs) present as brightly bordered cells with invisible cell nucleus, among which comparison reveals inhomogeneous reflectivity of the cytoplasm. Therefore, it is easy to identify BECs from other corneal epithelial cells because of their typical appearance and location, which is closely adjacent to the corneal stroma. To facilitate following analysis, the cells superficial to BECs were defined as corneal apical surface cells (ASCs) in this study, just as described in previous reports. ${ }^{9,10}$ ICs were characterized by round hyperreflective nucleus under LSCM with an average diameter of $<10 \mu \mathrm{m}$. DCs appeared to be hyperreflective corpuscular particles with dendritic processes, scattering among limbus or gathering in group. For each type of target cells, three images were randomly selected at each examination point according to the code, and a frame size of $200 \mu \mathrm{m} \times 200 \mu \mathrm{m}$ was randomly selected on each image. The cellular number within the frame was counted in manual mode (Cell Count Software; Heidelberg Engineering $\mathrm{GmbH}$ ) and the cellular densities were output by the software automatically. Then the average cellular densities were calculated.

\section{Statistical analysis}

The data were presented as mean \pm SD. Statistical analyses were performed with SAS (version 9.2; SAS Institute, Cary, NC, USA). Linear mixed model was used to compare the densities of corneal epithelial cells among subgroups and at subsequent follow-up time points. Student's $t$-test was performed to compare the cellular density between patients and normal control. Similar analyses were likewise performed concerning the densities of ICs and DCs infiltrating at the limbus. Nonparametric Spearman's rank correlation tests were performed to determine the correlations between the severity of injury and the presence rate of Palisades of Vogt (POV), as well as the densities of corneal epithelial cells. A $P$-value of $<0.05$ was considered as statistically significant.

\section{Results}

\section{The morphology of corneal epithelial cells}

Stratified epithelial cells could be identified in eyes classified as grade I and II at 1 month after injury. In eyes with grade III injury, only one layer of epithelial cells was visible on the edematous stroma at 1 month post injury. The recovery of stratified epithelia could not be found until 2 months after injury. Hardly could epithelial cells be detected in eyes classified as grade IV, even after 3 months post injury. Only denuded stroma and activated keratocytes were found under ISCM, without the covering of corneal epithelial cells or epithelium-like cells. The detailed morphology changes of corneal re-epithelialization following injury were shown in Figures 1 and 2.

\section{The densities of BECs and ASCS}

The average densities of ASCs and BECs in eyes with different injury severity were shown in Table 2 . The severity of injury had a significantly negative correlation with the densities of ASCs $(r=0.453, P=0.037)$. But it didn't have relationship with the densities of BECs. At 3 months after injury, the density of ASCs in eyes with either grade II or grade III injury was still significantly lower than that in normal eyes (grade II $v s$ normal: $P=0.012$, grade III $v$ s normal: $P<0.001$ ). As for the density of BECs in injured eyes, none of them had significant differences compared with normal subjects, as shown in Table 2. 

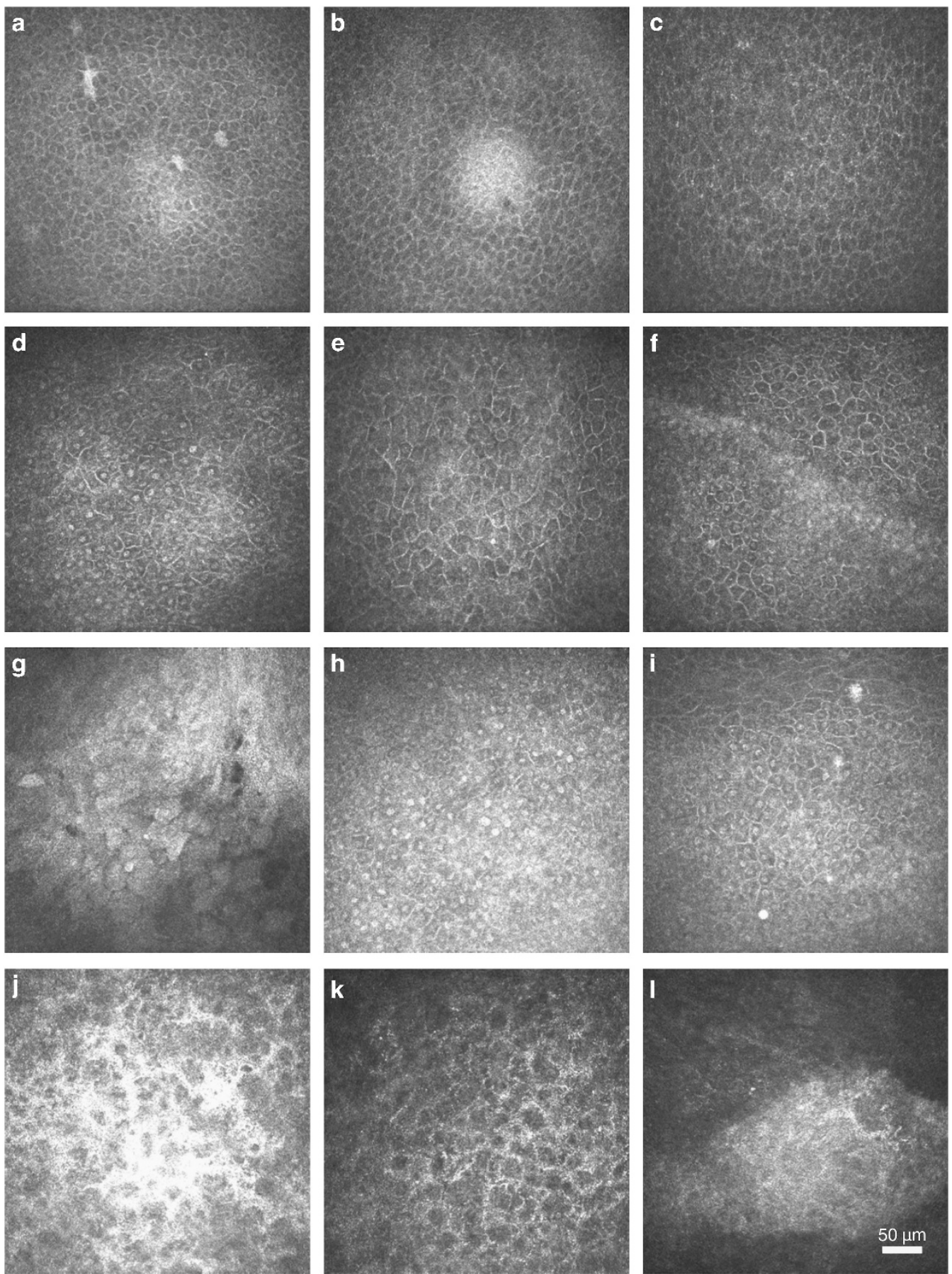

Figure 1 In vivo confocal microscopic images of ASCs in patients with grade I injury (the top row), grade II (the second row), grade III (the third row) and grade IV (the bottom row). Hardly could nuclei could be identified in ASCs in patients with grade I injury at 1 month, along with irregular cellular body (a). The recovery of the ASCs could be found at 2 months (b) and 3 months (c) after injury, which was characterized with a regular appearance resembling normal wing cells. ASCs in patients with grade II injury appeared to be more irregular at 1 month, with big hyperreflective nuclei and larger cellular body (d). At 2 months (e) and 3 months (f), N/C ratio and the size of cellular body decreased gradually. However, the irregular cellular arrangement was still visible at 3 months (f). The cellular borders could not be clearly distinguished in patients with grade III injury at 1 month (g). The cellular morphology resembling squamous superficial epithelial cells could be identified at 2 months (h), which had a more variable cellular size, prominent hyperreflective nuclei and high $\mathrm{N} / \mathrm{C}$ ratios. At 3 months, the $\mathrm{N} / \mathrm{C}$ ratios decreased apparently along with a clearer cell borders (i). The edematous stroma without epithelia covered and generally activated stromal cells were found in patients with grade IV injury at 1 month (j). The stroma edema gradually vanished at 2 months (k). However, the epithelial recovery could not be found even at 3 month (l), and only fibrosis in stroma was visible. 


\section{The morphology of limbus}

Typical POV were visible at the limbus in all healthy eyes, which were characterized by alternant epitheliumstromal cords with a bright fringe of hyperreflective BECs. No signs of ICs infiltration were found, only accompanied with a few DCs. After chemical injury, typical POV could be found in all mildly injured eyes and some moderately injured ones, which were similar to those seen in healthy eyes (Figure 3a). Atrophy POV was visible in some eyes with moderate injury, which presented to be the absence of hyperreflective BECs around stromal cords (Figure 3c). Numerous ICs were found to infiltrate at the limbus area in grade II, III, and IV at each time point, except grade II at 3 months after injury. DCs rather than ICs were identified at the limbus in eyes with grade I injury. In the eyes with severe chemical injury (grade III or IV), the formation of fibrous structure was found, along with the disappearance of typical POV (Figure $3 \mathrm{~d}-\mathrm{f}$ ). At 3 months after injury, the presence rates of POV in eyes classified as grade I, II, III, and IV were 100\% (5/5), 66.7\% (6/9), 66.7\% $(4 / 6)$, and $0(0 / 6)$, respectively.

\section{The densities of ICs and DCs}

The densities of DCs in chemically injured eyes were presented in Table 2. Even at 3 months after injury, the densities of DC in injured eyes were significantly higher than those in normal eyes (grade I vs normal: $P=0.012$, grade II $v$ s normal: $P<0.001)$. The density of ICs at the limbal area decreased significantly with the prolongation of duration after injury, as shown in Table 2. Spearman's rank correlation revealed that the density of ICs infiltrating the limbus had a positive correlation to the severity of injury at each time point after injury (1M: $r=0.849, P<0.001 ; 2 \mathrm{M}: r=0.585, P=0.011 ; 3 \mathrm{M}$ : $r=0.563, P=0.028)$. There was a close negative correlation between the presence rates of POV and the degrees of chemical injury $(r=0.620, P<0.001)$.

\section{Discussion}

The current study revealed that the early recovery of corneal epithelium after chemical injury varied according to the injury severity. In eyes classified as grade I injured, the normal morphology of corneal epithelial cells was found at 2 months after injury, indicating their rapid recovery. However, the eyes with grade II injury take longer time to obtain complete recovery. In the eyes classified as grade III injury, stratified epithelium had not been found until two months after injury. In the most severely injured eyes, being classified as grade IV, corneal epithelium recovery could not be found even at 3 months post injury. Our findings confirmed that the recovery of corneal epithelial cells had a close relationship with the injury severity.

We also found that the morphological changes of cornea epithelial cells in the chemically injured eyes mainly involved with three aspects. First, one layer of epithelial cells was transformed into stratified epithelium. At the first month after injury, the remaining epithelium in grade III was composed of only one layer of elliptical and large cells, which were not clearly distinguishable from each other. This finding suggested that the centripetal migration of remaining peripheral corneal epithelial cells occurred in order to quickly cover the denuded wound surface. ${ }^{9-11}$ Cho et $\mathrm{ll}^{12}$ also found that in rabbit corneas after epithelial debridement, the morphology of initially healing superficial cells were elliptical and large. Changes from single to multiple layers of corneal epithelia implied that epithelial differentiation occurred. Second, basal cellular borders reappeared during wound healing. The disappearance and subsequent reappearance of basal cellular borders during wound healing of grade II injury might suggest that the cellular junction reconstructed. ${ }^{9}$ At last, the nucleus/cytosol (N/C) ratios of epithelial cells decreased and the basal cellular nuclei subsequently disappeared as time went on. A large and hyperreflective nucleus may represent new, actively growing cells that are metabolically active and unstable, ${ }^{9}$ whereas decreased N/C ratios and subsequently disappeared nucleus inferred a return to normal and stable conditions. Those phenomena were also in accordance with the process of normal epithelial regeneration after epithelial debridement, which involved with three distinct but continuous stages of migration, differentiation, and reformation of hemidesmosomes. . $^{9,13,14}$

Apart from the morphology recovery of corneal epithelium, our study also found that the densities of ASCs were significantly lower in eyes with grade II and III injury at 2 months, compared with normal controls and eyes with grade I injury. However, at 3 months after injury, the densities of ASCs were similar among them. Thus, we deduced that the difference in the density of ASCs became less obvious with the prolonged duration after injury. In the present study, the densities of BECs in normal eyes were similar compared with previous reports. ${ }^{15-18}$ There are no significant differences between normal eyes and injured eyes concerning the densities of BECs, at 3 months after injury, except those with grade IV injury. Our finding suggested that the densities of BECs might be relatively stable during the epithelial recovery after chemical injury. Nevertheless, BECs were hardly found above the edematous stroma of central cornea in eyes classified as grade III at 1 month after injury. Kuwabara et $a l^{19}$ also found that the main sliding cells 

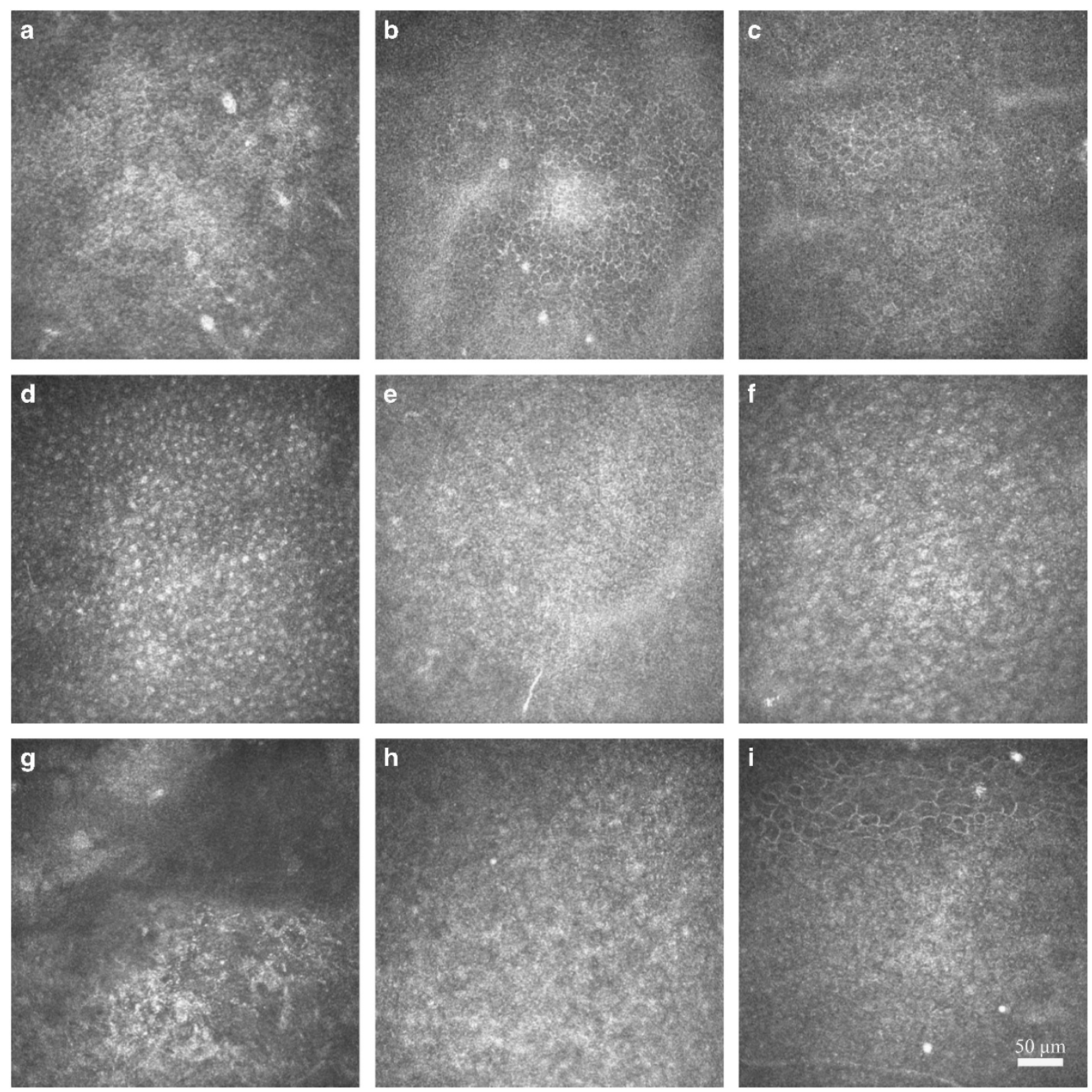

Figure 2 In vivo confocal microscopic images of BECs in patients with grade I injury (the top row), grade II (the second row), grade III (the third row) and grade IV (the bottom row). Nuclei were visible in patients with grade I injury at 1 month (a), accompanied with unclear cellular borders and irregular cellular reflection. The cellular body gradually became clear at 2 months (b) and 3 months (c), with only a few tiny nuclei were still visible. The cellular boundary was unclear in patients with grade II injury at 1 month (d), along with prominent nuclei and high N/C ratio. At 2 months (e) and 3 months (f), N/C ratio gradually decreased and the cellular boundary became clear. No BECs but edematous stroma could be found in patients with grade III injury at 1 month (g). Regenerated cells with unclear cellular boundary and prominent nuclei were visible at 2 months (h). At 3 months, the cellular boundary gradually became clear, with an irregular cellular size (i).

to initially cover a corneal epithelial defect after experimental corneal wounding were wing cells, and the basal cells were involved only to a minor extent. Severe destruction to the central cornea alone, in which the LSC population left largely intact, might lead to initial epithelial healing proceeding at a rate similar to that when the stem cell population has been destroyed, resulting from injury to basal lamina and anterior corneal stroma. ${ }^{20}$ To rapidly cover the denuded stroma, the epithelial cells flatten, migrate, and slide as a single- layered intact sheet in earlier corneal wound healing. ${ }^{21}$ Therefore, the damage to central cornea mainly contributed to delayed epithelial recovery in grade III injury. Although adhesion of the epithelium was greatly delayed and the rate of epithelial migration was slowed to half by absence of basal lamina, basal lamina has been proved not to be a prerequisite for the resurfacing of a corneal defect. Basal lamina, if injured in making the wound, was found to be re-formed only after migration was complete. ${ }^{19,22}$ 


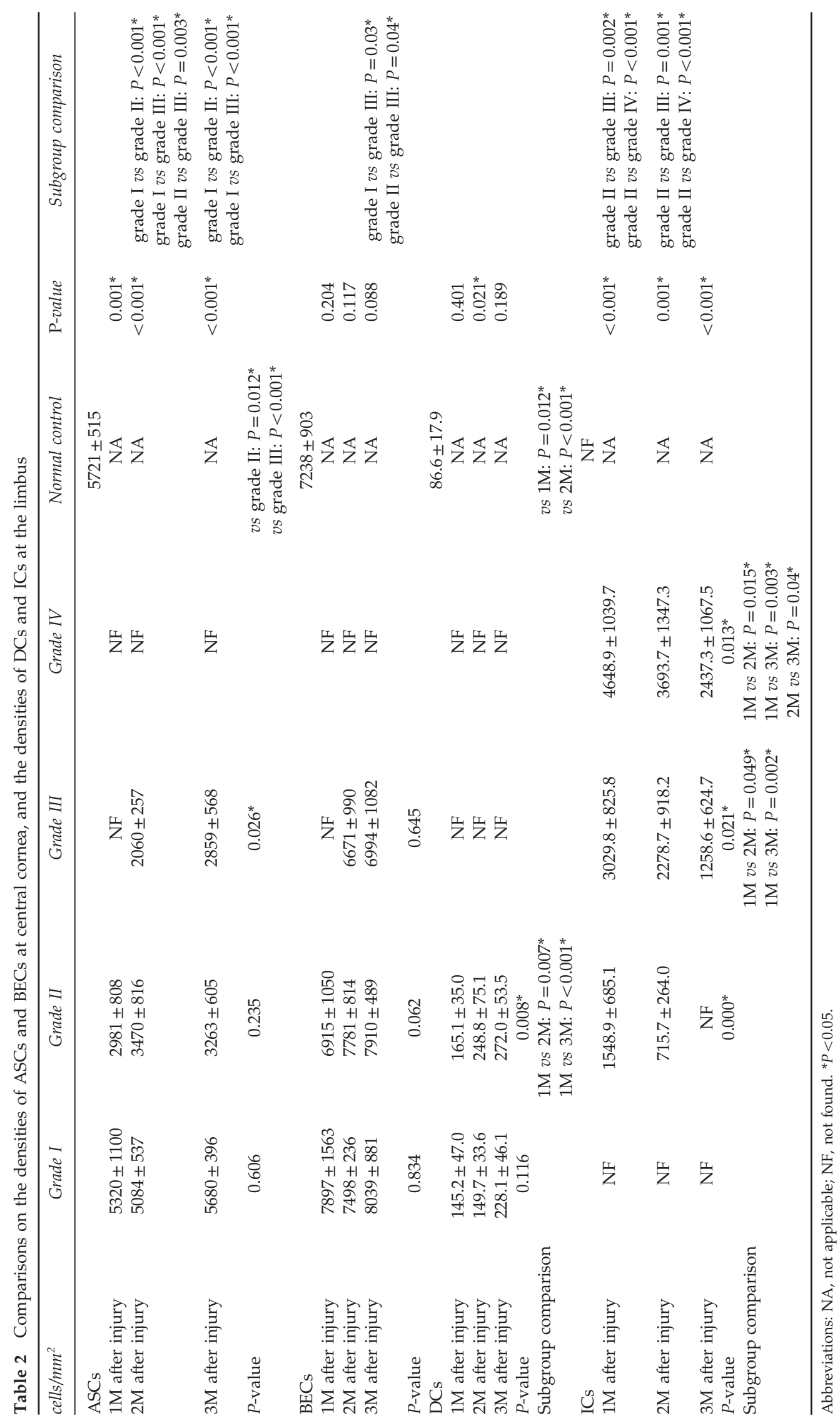



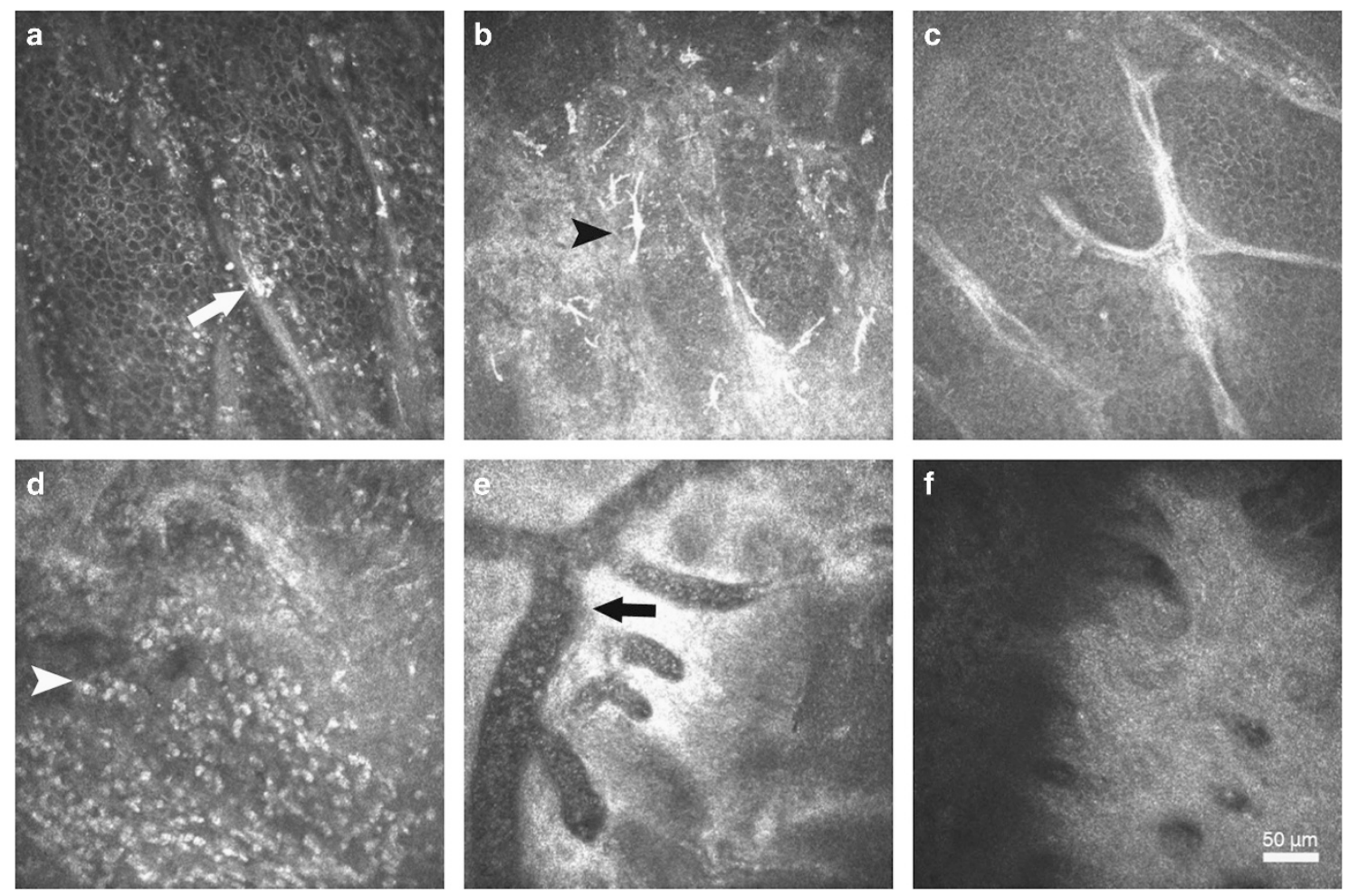

Figure 3 In vivo confocal microscopic images of limbus after ocular chemical injury. Typical image of the Palisades of Vogt (POV) was found in the eye with grade I injury (a), which was characterized by alternant epithelium-stromal cords with a bright fringe of hyperreflective basal epithelial cells. A few dendritic cells were visible (white arrow). More dendritic cells (black arrowhead) were found to infiltrate within the edematous epithelium-stromal cords in the eyes with grade II injury (b). The atrophic POV was identified in the eyes with grade III injury (c), which was characterized with the absence of hyperreflective basal epithelial cells around stromal cords. In the eyes with grade IV injury, numerous inflammatory cells (white arrowhead) instead of POV were found in the limbus (d), along with distinctly dilated vessels (e). At 3 months, the formation of acellular fibrous structure was found at limbus in the eyes with grade IV injury (f).

The presence rates of POV showed a close negative correlation with the degrees of chemical injury. As the POV are generally believed to harbor limbal stem cells (LSCs), they have been applied as a clinical marker to indicate the presence of LSCs. ${ }^{23}$ Therefore, lower presence rates of POV in high-level injury might imply that more LSCs were destroyed, which contributed to the failure of resurface the cornea by centripetal growth of corneal epithelium. Meanwhile, in the moderate and severe chemical injuries, we found that the considerable number of ICs infiltrated in the limbus, and their density was significantly increased with the aggravation of injury. Chronic inflammation in the limbus, the common denominator of limbal stem cell deficiency, had been confirmed to threaten the well-being of transplanted limbal autograft. ${ }^{24-26}$ Long-term ICs infiltration in the limbus may result in loss of LSCs and dysfunction of remaining LSCs, then leads to delay of corneal epithelial recovery. In eyes classified as grade I and II injury, DCs infiltration in the limbus was found. The density of DCs evaluated in this study was in accordance with those in the inflamed eyes reported by Mastropasqua. ${ }^{27}$
In conclusion, we found that epithelial recovery after chemical injury varied in morphology and densities of ASCs according to the degrees of ocular injury, and the presence rates of POV decreased with the aggravation of injury. LSCM was a feasible method for observing the early recovery of corneal epithelium in patients with chemical injuries.

\section{Summary}

\section{What was known before}

- Corneal epithelium defect may occur soon after chemical burns and last for a long time. The clinical assessment of corneal epithelium recovery mainly depends on slit lamp microscopy at present. The morphological changes of the POV have been investigated only in patients with chronic limbal stem cell deficiency after chemical injury.

\section{What this study adds}

- Corneal epithelium recovery after chemical injury varied in cellular morphology, which had a close relationship with injury severity. The presence rates of the POV decreased with the aggravation of injury. Confocal microscopy is a feasible method to evaluate the early recovery of corneal epithelium after chemical injuries. 


\section{Conflict of interest}

The authors declare no conflict of interest.

\section{Acknowledgements}

Financial support: National Science and Technology Research Program, the Ministry of Science and Technology, China (2012BAI08B01); National Natural Science Foundation of China (81170817, 81270014, 81200658); Scientific Research Program, Science and Technology Commission of Shanghai Municipality, Shanghai (11231200602, 11DZ2260900). The sponsor or funding organization had no role in the design or conduct of this research.

\section{References}

1 Brodovsky SC, McCarty CA, Snibson G, Loughnan M, Sullivan L, Daniell M et al. Management of alkali burns: an 11year retrospective review. Ophthalmology 2000; 107: 1829-1835.

2 Tseng SCG. Regulation and clinical implications of corneal epithelial stem cells. Mol Biol Rep 1996; 23: 47-58.

3 Zheng T, Xu J. Age-related changes of human limbus on in vivo confocal microscopy. Cornea 2008; 27: 782-786.

4 Lagali N, Fagerholm P. Corneal injury by formic acid: one-year clinical course and in vivo confocal microscopic evaluation. Clin Experiment Ophthalmol 2008; 36: 692-694.

5 Le Q, Wang W, Hong J, Sun X, Zheng T, Zhu W et al. An in vivo confocal microscopy and impression cytology analysis of goblet cells in patients with chemical burns. Invest Invest Ophthalmol Vis Sci 2010; 51: 1397-1400.

6 Nubile M, Lanzini M, Miri A, Pocobelli A, Calienno R, Curcio $\mathrm{C}$ et al. In vivo confocal microscopy in diagnosis of limbal stem cell deficiency. Am J Ophthalmol 2013; 155: 220-232.

7 Hong J, Zheng T, Xu J, Deng SX, Chen L, Sun X et al. Assessment of limbus and central cornea in patients with keratolimbal allograft transplantation using in vivo laser scanning confocal microscopy: an observational study. Graefes Arch Clin Exp Ophthalmol 2011; 249: 701-708.

8 Roper-Hall M. Thermal and chemical burns. Trans Ophthalmol Soc UK 1965; 85: 631.

9 Chen WL, Chang HW, Hu FR. In vivo confocal microscopic evaluation of corneal wound healing after epi-LASIK. Invest Ophthalmol Vis Sci 2008; 49: 2416-2423.

10 Chen WL, Shen EP, Hsieh YT, Yeh PT, Wang TJ, Hu FR. Comparison of in vivo confocal microscopic findings between epi-LASIK procedures with different management of the epithelial flaps. Invest Ophthalmol Vis Sci 2011; 52: 3640-3647.

11 Chen WL, Lin CT, Ko PS, Yeh PT, Kuan YH, Hu FR et al. In vivo confocal microscopic findings of corneal wound healing after corneal epithelial debridement in diabetic vitrectomy. Ophthalmology 2009; 116: 1038-1047.
12 Cho BJ, Djalilian AR, Holland EJ. Tandem scanning confocal microscopic analysis of differences between epithelial healing in limbal stem cell deficiency and normal corneal reepithelialization in rabbits. Cornea 1998; 17: 68-73.

13 Zieske JD, Gipson IKAgents that affect corneal wound healing: modulation of structure and function. In: Albert DM, Jakobiec FA (eds). Principles and Practice of Ophthalmology. WB Saunders: Philadelphia, PA, USA, 2000, pp 364-372.

14 Gipson IK, Spurr-Michaud SJ, Tisdale AS. Anchoring fibrils form a complex network in human and rabbit cornea. Invest Ophthalmol Vis Sci 1987; 28: 212-220.

15 Eckard A, Stave J, Guthoff RF. In vivo investigations of the corneal epithelium with the confocal Rostock Laser Scanning Microscope (RLSM). Cornea 2006; 25: 127-131.

16 Patel DV, Sherwin T, McGhee CNJ. Laser scanning in vivo confocal microscopy of the normal human corneoscleral limbus. Invest Ophthalmol Vis Sci 2006; 47: 2823-2827.

17 Niederer RL, Perumal D, Sherwin T, McGhee CNJ. Age-related differences in the normal human cornea: a laser scanning in vivo confocal microscopy study. Br J Ophthalmol 2007; 91: 1165-1169.

18 Niederer RL, Perumal D, Sherwin T, McGhee CNJ. Laser scanning in vivo confocal microscopy reveals reduced innervation and reduction in cell density in all layers of the keratoconic cornea. Invest Ophthalmol Vis Sci 2008; 49: 2964-2970.

19 Kuwabara T, Perkins DG, Cogan DG. Sliding of the epithelium in experimental corneal wounds. Invest Ophthalmol 1976; 15: 4-14.

20 Pfister RR, Burstein N. The alkali burned cornea I. Epithelial and stromal repair. Exp Eye Res 1976; 23: 519-535.

21 Wilson SE, Liu JJ, Mohan RR. Stromal-epithelial interactions in the cornea. Prog Retin Eye Res 1999; 18: 293-309.

22 Blümcke S, Rode J, Niedorf H. Formation of the basement membrane during regeneration of the corneal epithelium. Cell Tissue Res 1968; 93: 84-92.

23 Kinoshita S, Adachi W, Sotozono C, Nishida K, Yokoi N, Quantock AJ et al. Characteristics of the human ocular surface epithelium. Prog Retin Eye Res 2001; 20: 639-673.

24 Espana EM, Di Pascuale MA, He H, Kawakita T, Raju VK, Liu CY et al. Characterization of corneal pannus removed from patients with total limbal stem cell deficiency. Invest Ophthalmol Vis Sci 2004; 45: 2961-2966.

25 Tsai R, Tseng S. Effect of stromal inflammation on the outcome of limbal transplantation for corneal surface reconstruction. Cornea 1995; 14: 439-449.

26 Li W, Hayashida Y, Chen YT, Tseng SCG. Niche regulation of corneal epithelial stem cells at the limbus. Cell Res 2007; 17: 26-36.

27 Mastropasqua L, Nubile M, Lanzini M, Carpineto P, Ciancaglini M, Pannellini T et al. Epithelial dendritic cell distribution in normal and inflamed human cornea: in vivo confocal microscopy study. Am J Ophthalmol 2006; 142: 736-744. 